\title{
IDHM dos Estados da Região Nordeste do Brasil: Histórico e Análise entre 1991 e 2010
}

\author{
Uirá Araújo Nery da Cunha ${ }^{1}$; Liliane Caraciolo Ferreira ${ }^{2}$
}

\begin{abstract}
Resumo: A região Nordeste do Brasil historicamente sofreu por diversas mudanças demográficas e étnicas ao longo do processo de colonização e formação da república. Tal formação conjuntural atrelada às condições climáticas peculiares da região repercutiu decisivamente na questão regional e seu desenvolvimento socioeconômico. A análise do IDH (Índice de Desenvolvimento Humano), calculado pelo IBGE a nível municipal e apresentado a nível estadual, foi realizada entre os anos de 1991 e 2010, tomando três anos como base de dados (1991,2000 e 2010). O acompanhamento específico de quatro variáveis (IDHM, IDHM Renda, IDHM Saúde e IDHM Educação ) dos estados da federação (incluindo o Distrito Federal) foi realizado com o foco principal da evolução das variáveis de desenvolvimento humano frente às disparidades regionais existentes e possíveis inferências quanto à problemática nos próximos anos.
\end{abstract}

Palavras-chave: Nordeste do Brasil, Índice de Desenvolvimento Humano, evolução, disparidades regionais.

\section{IDHM of the States of the Northeast of Brazil: History and Analysis between 1991 and 2010}

\begin{abstract}
The Northeast region of Brazil historically suffered WITH several demographic and ethnic changes over colonization and the republic formation process. Such cyclical training linked to the peculiar climatic conditions of the region rebounded decisively in the regional issue and its socio-economic development. The analysis of the HDI (Human Development Index), calculated by IBGE at the municipal level and presented at the state level, was carried out between the years 1991 and 2010, taking three years as database (1991.2000 and 2010). The specific monitoring of four variables (IDHM, IDHM income, IDHM Health and IDHM Education) of the federation states (including the Federal District) was held with the main focus of the evolution of human development variables in the face of regional disparities and possible inferences as the problem in the coming years.
\end{abstract}

Keywords: Northeast Brazil, the Human Development Index, development, regional.

\section{Introdução}

A região Nordeste, local de início da colonização do país, exploração das atividades econômicas da colônia, região que abrigou a primeira capital do Brasil teve papel fundamental na formação demográfica e étnica. Considerando as informações do Cadastro Único (base de dados para administração do principal programa social em vigência no território nacional), o Bolsa Família possui mais de 50\% dos seus recursos destinados a famílias nordestinas (MDS, 2016).

\footnotetext{
${ }^{1}$ Bacharel em Administração pela Fundação Universidade Federal do Vale do São Francisco (UNIVASF). E-mail: uira araujo@hotmail.com ${ }^{2}$ Doutora em Psicologia. Professora do Colegiado de Administração da Universidade Federal do Vale do São Francisco (UNIVASF). E-mail: liliane.ferreira@univasf.edu.br
} 
Observa-se desde o período colonial, o início da disparidade regional, a ampliação da vantagem competitiva do Sudeste e do Sul do país ao mesmo tempo que tornava-se evidente o empobrecimento ainda maior das demais regiões, principalmente a região nordeste. Segundo Furtado (2005, pg. 233), na metade do século XX, apesar do grau de articulação comercial entre as regiões, a divergência dos níveis de renda inter-regionais haviam ampliado. Após uma reforma tarifária ocorrida no Nordeste, em 1844, até 1910 tem-se que a quantidade de operários da indústria têxtil da região era semelhante à quantidade de operários do Estado de São Paulo. Com o passar do tempo, após a primeira guerra mundial, houve uma tendência de aglutinação das industrias em determinada local geográfico, no caso o estado de São Paulo.

Segundo Furtado (2007, pg. 234), em 1920, 29,1\% dos operários das indústrias estavam localizados no estado de São Paulo, contra $27 \%$ de operários industriais em toda a região Nordeste. Já em 1950, apenas 30 anos depois, o percentual de operários no estado de São Paulo passou para 38,6\%, e a quantidade de operários na região nordeste caiu para 12,9\% do total. Daí observou-se a necessidade de utilização de mecanismos políticos de intervenção, na tentativa de desenvolver o país de forma igualitária e isonômica, tratando os desiguais de maneira desigual.

Pode-se evidenciar o histórico inicial das diversidades geográficas da região Nordeste atreladas às atividades econômicas realizadas com um alto índice de produtividade, mais próximo ao litoral com a cana de açúcar, e a pecuária extensiva que interiorizou-se, bem como a forma de interiorização a nível cultural da execução da atividade, conforme Ribeiro (2006). Sendo assim, com a implantação do Índice de Desenvolvimento Humano nos municípios brasileiros foi uma grande ferramenta de mensuração da evolução e demandas sociais a serem implementadas como forma de equalizar o desenvolvimento inter-regional, visando a minimização das disparidades entre os indicadores socioeconômicos das regiões brasileiras. Trata-se de um grande desafio num país de dimensões continentais e enormes diversidades geográficas, culturais, econômicas e étnicas.

O Nordeste brasileiro representa a terceira região mais extensa do país, com área oficial de 155.4291,744 $\mathrm{km}^{2}$ (IBGE, 2016), aproximadamente 18,25\% do território nacional, constituindo 9 Estados da Federação (Alagoas, Bahia, Ceará, Maranhão, Paraíba, Pernambuco, Piauí, Rio Grande do Norte e Sergipe). Em convergência ao determinado através do Anexo I da Portaria $\mathrm{N}^{\circ}$ 89, de 16 de março de 2005, do Ministério da Integração Nacional, que discrimina todos os municípios que situados no semiárido, do total que abrange área aproximada de $982.563,3 \mathrm{~km}^{2}$ (incluindo 10,5\% situado no Norte do Estado de Minas Gerais), cerca de 56,58\% da área da região Nordeste é coberta pelo semiárido (Portaria $\mathrm{N}^{\circ} 89$ ). Caracteriza-se por ser uma região de hidrografia frágil, sem condições de possibilitar rios caudalosos, onde a única exceção é o Rio São Francisco, rio perene fundamental para a vida e possibilidades de desenvolvimento no semiárido (IBGE, 2016). 


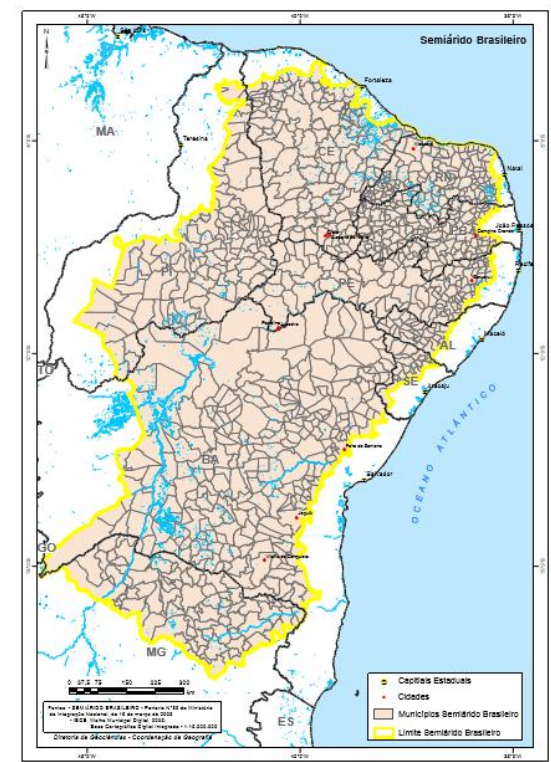

Figura 1 - Semiárido Brasileiro (2005)

Pode-se observar que as únicas regiões situadas fora do semiárido brasileiro na região Nordeste são o Estado do Maranhão, oeste do Piauí (área de transição entre caatinga e a floresta tropical), oeste da Bahia (cerrado), agreste (transição entre o litoral e semiárido) e quase toda a totalidade da região litorânea do Nordeste (IBGE. Semiárido brasileiro. 2005).

Alguns conceitos devem ser abordados previamente ao foco do estudo para abranger pontos pertinentes da análise, como a idéia de produção, crescimento e desenvolvimento econômico. Produção representa o envolvimento dos fatores de produção (terra, trabalho e capital) com o enfoque de atender necessidades humanas. Assim, o crescimento econômico, é definido como "o aumento do produto naquele período, ou seja, a elevação na produção de bens e serviços que satisfaçam as necessidades humanas" (GREMAUD, et al, p. 54, 2007). Já o conceito de desenvolvimento econômico, que também aglomera o crescimento econômico, vai além da ampliação da produção. Tal conceito está ligado "às condições de vida da população ou à qualidade de vida dos residentes no país". Obviamente, tais aspectos denotam relativa subjetividade, pois o próprio conceito de qualidade de vida de uma população aborda aspectos culturais, que são relativos.

Outra mensuração bem comum é o produto per capita, ou PIB per capita, que realiza a mensuração entre o produto de determinado local num período determinado e faz a razão entre a população absoluta. Obviamente, tal mensuração denota que, quanto maior for o produto per capita, maior será a tendência de determinada população ter necessidades realizadas (GREMAUD, et al, p. 81, 2007). Também, outros fatores que não se enquadram em aspectos econômicos devem ser levados em consideração, pois: 
"Se o desenvolvimento econômico de um país é definido pela qualidade de vida de seus habitantes, não se pode examinar apenas o crescimento da produção de bens desse país. Além disso, o conceito de PIB per capita, apesar de já ser um avanço, também precisa ser complementado com outros elementos. Por um lado, temos que analisar os chamados aspectos distributivos da renda nesse país; por outro, há que se levar em conta os chamados indicadores sociais desse país" (GREMAUD, et al. P. 83. 2007).

O IDH (Índice de Desenvolvimento Humano) foi criado por Mahbub ul Haq e teve a colaboração do economista Amartya Sen, e teve a idéia de representar o desenvolvimento humano. Tal índice tem uma escala entre 0 e 1 , onde quanto mais próximo de 1 maior será o grau de desenvolvimento do país que atualmente está focado em três pilares básicos, que são:

- Saúde, com um indicador que mensure longevidade;

- Educação, representado por uma média ponderada entre a taxa alfabetização e adultos e taxa de matrícula de alunos em período escolar;

- Renda, com a mensuração do PIB per capita;

No Brasil, outra adoção realizada é a adoção do IDH-M (Índice de Desenvolvimento Humano Municipal), bem como as mensurações dos três pilares básicos do cálculo do IDH (IBGE. 2016), citados abaixo:

- Saúde, medida através da expectativa de vida;

- Educação, medida basicamente através da quantidade de anos no ensino regular, sejam adultos que iniciaram tardiamente ou crianças que estão ingressando;

- Renda, medida através da Renda Nacional Bruta (RNB);

Pode-se observar grande convergência entre os modelos adotados, justamente por conta da padronização.Trata-se de um enfoque diferenciado de análise, frente às medidas de desenvolvimento econômico. Como o PIB per capita é uma media, a questão da distribuição de renda grau de concentração de renda e determinadas classes ainda é um ponto a ser bastante discutido. Um outro índice que auxilia nesta análise é o índice de Gini, calculado a partir da curva de Lorenz, onde há a representação do percentual de determinada população no eixo das abscissas e o eixo das ordenadas representa o percentual de renda acumulada. A Curva de Lorenz é uma reta que liga a origem do percentual da população acumulada à totalidade do percentual da renda acumulada. Sendo assim, quanto maior for a proximidade da curva em determinado período de determinado país, maior será o grau de distribuição de renda e quanto mais distante da curva de Lorenz, menor será o grau de distribuição de renda entre a população. 


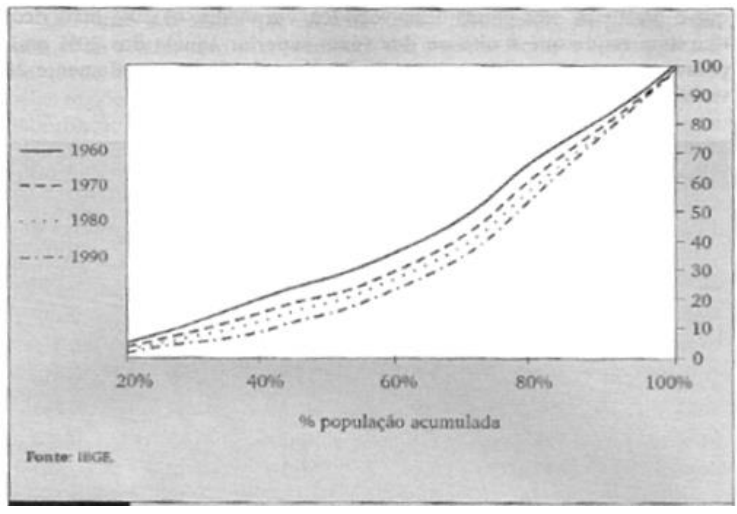

Figura 2 - Gráfico da curva de Lorenz da situação brasileira entre 1960 -1990. (GREMAUD, et al, p 94. 2007).

A partir da figura 2 pode-se observar que no período houve ampliação da desigualdade de renda da população brasileira. Dois pontos podem auxiliar a subsidiar os motivos, onde:

- O processo de substituição de importações possibilitou utilização de recursos tecnológicos que influenciaram no aumento da capacidade operacional com menor exigência de mão de obra, aumentando a lucratividade dos empresários e acirrando as disputas de mão de obra (com grande quantidade disponível no mercado), auxiliando a multiplicar o poder de barganha dos detentores do capital e diminuir a remuneração sobre a mão de obra.

\section{Método}

Conforme GIL (2002), a presente pesquisa terá a característica exploratória, classificada conforme o objetivo, "com vistas a torná-lo mais explícito ou a constituir hipóteses. Pode-se dizer que estas pesquisas têm como objetivo principal o aprimoramento de idéias ou a descoberta de intuições" (GIL, 2002, p. 41). Já com base nos procedimentos técnicos a serem utilizados, a presente pesquisa constitui-se basicamente de uma pesquisa documental, com foco nas informações apresentadas por órgãos oficiais, sendo o principal deles o Instituto Brasileiro de Geografia e Estatística (IBGE). Em virtude de tratar-se de uma pesquisa essencialmente analítica de uma situação histórica regional bem como um panorama futuro acerca dos dados coletados na atualidade, tem-se uma forma de estudo que não contará com nenhuma forma de intervenção direta do pesquisador sob o meio do objeto de estudo (Vegara, 1997).

Pode-se ressaltar que a priori não haverá tratamento estatístico com as informações, entretanto haverá utilização de planilha eletrônica para organização e tratamento de alguns dados entre 1990 e 2010 para classificação, mensuração de variações e confecção de gráficos (para abordagem focada na variação de dados). A expectativa do presente trabalho é servir como norteador de políticas públicas e 
Id on Line Revista Multidisciplinar e de Psicologia

Id on Line Multidisciplinary and Psychology Journal

inferir o panorama específico da região Nordeste para a próxima década, com foco na diminuição das desigualdades interregionais. A planilha eletrônica utilizada é Microsoft Excel 2007, adotando a seguinte formatação abaixo:

- Para os índices e médias: 4 casas decimais antes da vírgula;

- Para os percentuais de variação: 2 casas decimais antes da vírgula;

Cabe ressaltar que para o cálculo de variação fora utilizada a seguinte fórmula abaixo para todss as variações:

$$
\mathrm{V} \%=\frac{\mathrm{B}-\mathrm{A}}{\mathrm{ABS}(\mathrm{A})}
$$

Onde:

V\%: Variação percentual;

B: Valor do IDH em exercício posterior;

A: Valor do IDH em exercício anterior;

ABS(A): Valor absoluto da variável "A";

O cálculo de média foi utilizada a função MÉDIA do referido aplicativo utilizado, que realiza a seguinte função:

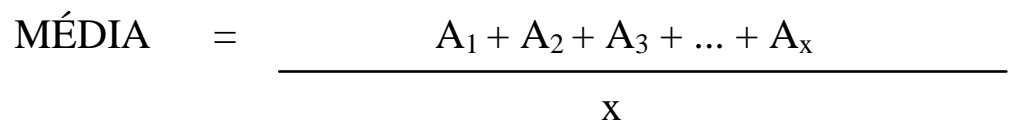

A mensuração dos índices de desenvolvimento humano dos municípios brasileiros foi tomado sob quatro perspectivas diferenciadas: IDHM (geral), IDHM Renda (mensuração a partir da Renda Nacional Bruta), IDHM Longevidade (evidenciada a partir das ações em saúde que promovem melhoria de vida conseqüentemente ampliação da longevidade da população) e IDHM Educação (medida basicamente quantitativa). Os anexos indicam:

- Anexo I: Quadro do ranking do IDH dos Estados e Distrito Federal do ano de 1991 (ordenados alfabeticamente);

- Anexo II: Quadro do ranking do IDH dos Estados e Distrito Federal do ano de 2010 (ordenados alfabeticamente); 
Id on Line Revista Multidisciplinar e de Psicologia

Id on Line Multidisciplinary and Psychology Journal

- Anexo III: Quadro da variação percentual dos Estados e Distrito Federal entre 1991 e 2010 (ordenados alfabeticamente);

A partir desta da base de dados fora analisado o comportamento e a evolução percentual das variáveis nos Estados da Federação e Distrito Federal, onde na Tabela 1 pode-se evidenciar as médias do IDHM nos exercícios de 1991 e 2010 sob três focos:

- Brasil: Média aritmética de todos os estados da federação +Distrito Federal;

- Brasil (exceto Nordeste): Média aritmética de todos os Estados + Distrito federal, excluindo os 9 Estados da Região Nordeste;

- Nordeste: Média aritmética de todos os estados que compõem a região Nordeste;

Sendo assim, é possível evidenciar que o IDHM da região Nordeste, por ser menor e representativo ( com 1/3 dos Estados da federação) acabou influenciando o IDHM geral da do país, por fazer parte do quantitativo analisado e exercer influência direta na representação. Tal fato repetiuse tanto na análise do exercício de 1991 quanto na análise da média efetuada no ano de 2010, conforme Tabela 1 a seguir.

Tabela 1 - Média dos índices nos exercícios de 1991- 2010.

\begin{tabular}{|r|l|c|c|c|c|}
\hline Ano & \multicolumn{1}{|c|}{ País / Região } & Ranking IDHM & IDHM Renda & $\begin{array}{c}\text { IDHM } \\
\text { Longevidade }\end{array}$ & $\begin{array}{c}\text { IDHM } \\
\text { Educação }\end{array}$ \\
\hline 1991 & Brasil & 0,4539 & 0,5992 & 0,6446 & 0,2456 \\
\hline 1991 & Nordeste & 0,3931 & 0,5279 & 0,5830 & 0,1981 \\
\hline 1991 & Brasil (exceto Nordeste) & 0,4843 & 0,6348 & 0,6754 & 0,2693 \\
\hline 2010 & Brasil & 0,7045 & 0,7069 & 0,8086 & 0,6124 \\
\hline 2010 & Nordeste & 0,6598 & 0,6534 & 0,7789 & 0,5650 \\
\hline 2010 & Brasil (exceto Nordeste) & 0,7269 & 0,7336 & 0,8235 & 0,6361 \\
\hline
\end{tabular}

Fonte: Atlas do desenvolvimento Humano dos Municípios.

Em contrapartida às variáveis supracitadas, observa-se através da Tabela 2 (vide abaixo), que a variação percentual mais acentuada entre 1991 e 2010 foi justamente na região Nordeste. Tal indicador denota que a melhoria dos índices foi mais acentuada na região que deteve os menores índices é um indicador extremamente pertinente por apontar percentual de melhora acima da média, se comparado às outras regiões do país. 
Id on Line Revista Multidisciplinar e de Psicologia

Id on Line Multidisciplinary and Psychology Journal

Tabela 2 - Evolução percentual da média dos índices entre 1991-2010.

\begin{tabular}{|l|r|r|r|r|}
\hline \multicolumn{1}{|c|}{ Ano } & Variação Ranking & $\begin{array}{c}\text { Variação } \\
\text { Renda }\end{array}$ & $\begin{array}{c}\text { Variação } \\
\text { Longevidade }\end{array}$ & $\begin{array}{c}\text { Variação } \\
\text { Educação }\end{array}$ \\
\hline $1991-2010$ (BRASIL) & $55,21 \%$ & $17,98 \%$ & $25,44 \%$ & $149,40 \%$ \\
\hline $1991-2010$ (NORDESTE) & $67,83 \%$ & $23,78 \%$ & $33,60 \%$ & $185,19 \%$ \\
\hline $\begin{array}{l}1991-2010 \text { (EXCETO } \\
\text { NORDESTE) }\end{array}$ & $50,08 \%$ & $15,56 \%$ & $21,92 \%$ & $136,23 \%$ \\
\hline
\end{tabular}

Fonte: Atlas do desenvolvimento Humano dos Municípios.

\section{Discussão}

A seguir, pode-se observar dois gráficos, que mostram as médias dos índices de desenvolvimento humano dos municípios das médias do país e das médias alcançadas da região Nordeste, no mesmo período de análise, entre 1991-2010, bem como verificar a tendência de evolução das variáveis ao longo do tempo.

Gráfico 1 - Evolução da média das variáveis de IDHM do Brasil 1991-2010

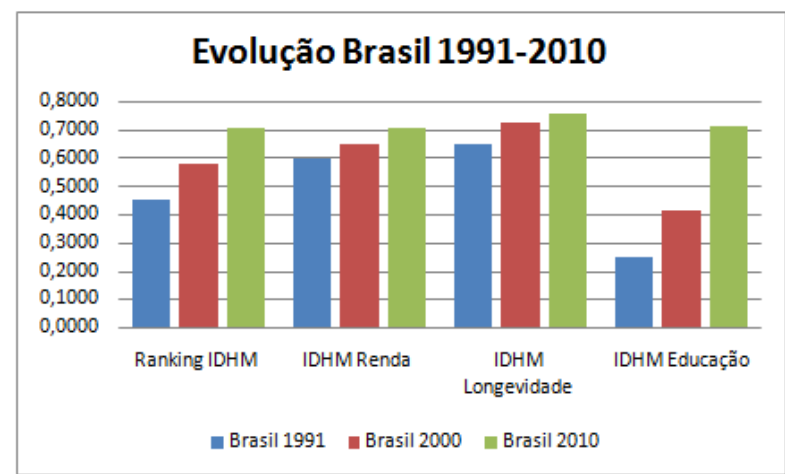

Fonte: Atlas do desenvolvimento Humano dos Municípios.

Gráfico 2 - Evolução da média das variáveis de IDHM da região Nordeste do Brasil 1991-2010

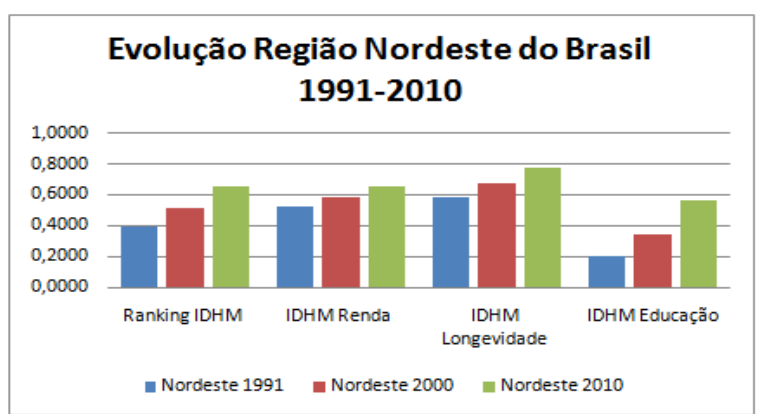

Fonte: Atlas do desenvolvimento Humano dos Municípios. 
Os gráficos dispostos demonstram o comportamento semelhante de crescimento dos indicadores em todos os casos, tanto na situação dos índices a nível de Brasil quanto das variáveis a nível regional. Tal fator indica coerência e até relativa convergência das políticas públicas que refletiram melhoria dos índices, apesar das variações a nível de país sofrerem influência das variações ocorridas na região Nordeste, também pode-se observar variação positiva quando a região Nordeste foi retirada da análise. Apesar da variação positiva superior às demais regiões do Brasil é possível determinar alguns aspectos decisivos em políticas públicas que auxiliaram na melhoria do IDHM para a região Nordeste, onde cada aspecto do IDHM está detalhado a seguir:

\section{- IDHM-Renda:}

- Sob este aspecto, pode-se inferir que as principais motivações para ampliação da renda da população dos municípios da região Nordeste foi afetada diretamente através de políticas públicas a nível Federal, atualmente denominado Cadastro Único, sob responsabilidade do Ministério do Desenvolvimento Social e Combate à Fome (MDS,2016);

- Em 2010, a população da região Nordeste alcançou a marca de 53 milhões de habitantes, cerca de $27,83 \%$ da população brasileira (IBGE, 2016), e concentrou $42,51 \%$ do total de famílias beneficiadas no programa Bolsa-Família no mesmo ano, o maior programa de distribuição de renda do programa Cadastro Único (MDS, 2016);

- Atualmente, o Cadastro Único é a única forma de acesso aos programas sociais, que trabalha com os seguintes programas abaixo:

- Programa Bolsa Família;Tarifa Social de Energia elétrica;Programa Minha Casa Minha Vida;Carteira do Idoso;Aposentadoria para pessoas de baixa renda;Telefone Popular;Isenção de pagamento de taxa de inscrição em concursos públicos;Água para todos;Bolsa Verde;Bolsa Estiagem;Programa de fomento às atividades rurais produtivas/ Assistência técnica e extensão rural;Programa nacional de reforma agrária;Programa nacional de crédito fundiário;Crédito instalação;Carta Social;Serviços assistenciais;Programa Brasil Alfabetizado; Programa de erradicação do trabalho infantil (Peti);

- Com tal portfólio de políticas públicas é totalmente viável inferir que tais programas foram determinantes à variação do IDHM-Renda da região Nordeste acima das demais regiões do país;

- Há outro ponto extremamente pertinente quanto à questão da evolução do salário mínimo , pois entre 1994 (Lei 8.880 de 27/05/94) e 2010 (Lei n 12.255 de 15.06.201), partiu de $\mathrm{R} \$ 64,79$ para $\mathrm{R} \$ 510,00$, mesmo considerando a inflação do período, houve aumento real de renda.

- IDHM-Longevidade:

- Com a CF/88, foi incluída a promoção da saúde de forma gratuita, ampla e preventiva. Tais políticas públicas, principalmente a formalização do SUS (Sistema Único de Saúde), através das leis n 8.080/90 e 8.142/90;

- Nota-se a continuidade da formalização de políticas públicas que ampliaram de forma direta a questão da saúde, como o próprio Bolsa- Família, a criação das farmácias populares e a implantação de remédios genéricos;

- IDHM-Educação:

- Tal variável foi a que apresentou a maior variação positiva frente às demais, inclusive na região Nordeste. Entretanto tal variação é questionável em virtude de ser uma variável quantitativa, indicando a evolução à acessibilidade ao ensino regular. Apesar de diversas políticas públicas de ampliação ao acesso da educação básica ao ensino público de nível superior e tecnológico, há necessidade do refinamento qualitativo para melhor compreensão do atual estágio da educação bem como a correlação do estágio com o IDHM-Educação;

- Pode-se citar como uma política pública que auxiliou na melhoria generalizada da variável foi o programa "Caminho da escola", promovido por uma política do Fundo Nacional de Desenvolvimento da Educação, onde houve o fornecimento de renovação de frota escolar para utilização no transporte de estudantes da rede estadual e municipal, fornecendo transporte diário e gratuito aos estudantes que residem na zona rural dos municípios, possibilitando o fortalecimento do vínculo estudantil e propiciando redução da evasão escolar. 


\section{Conclusões}

Desta forma, apesar dos avanços das variáveis de IDHM na região Nordeste terem sido extremamente favoráveis, inclusive em comparação a outras regiões brasileiras, observa-se extrema correlação entre a quantidade de políticas públicas e recursos públicos investidos, especialmente na saúde e educação, e variação positiva nas variáveis de IDHM. Inclusive tal discussão deve ser motivo de novos estudos em busca do aperfeiçoamento de políticas públicas, na melhoria da utilização e aperfeiçoamento a nível de controle do orçamento público, na integração entre entes públicos e no papel fundamental do gestor público como agente propulsor do desenvolvimento e bem-estar social.

O Nordeste brasileiro tem grandes desafios nos próximos anos, principalmente frente à questão climática na região do semiárido e esta questão pode influenciar a demografia regional. Apesar disto, a quantidade de políticas públicas a nível regional devem continuar exercendo forte influência positiva nos aspectos sociais, na melhoria da qualidade de vida, no acesso digno à educação e à saúde, na promoção do desenvolvimento econômico, geração de empregos, geração de renda e continuidade da melhoria dos índices de desenvolvimento humano nos municípios da região nordeste e no país.

Mesmo com os elevados impactos a nível quantitativo frente à melhoria dos índices de desenvolvimento humano dos municípios, pode-se verificar que tal análise ocorreu de forma equivalente e tal melhoria acima da média denota avanços de acesso à educação, de acesso à saúde e melhoria na distribuição de renda (as três principais variáveis). Apesar do hiato ainda existente entre algumas regiões do país a nível socioeconômico pode-se observar uma melhor equalização entre os indicadores do Brasil e dos indicadores do Nordeste, com tendência à média do Brasil, exclusive Nordeste. Apesar da grande responsabilidade do poder público sobre as modificações de indicadores sociais, existem avanços significativos que denotam a continuidade de políticas públicas de amplo acesso, mesmo com situações macroambeintais que possam afetar progressos relevantes na década corrente.

\section{Referências}

FNDE. Programa Caminho da Escola. Disponível em: $<$ http://www.fnde.gov.br/programas/caminho-da-escola/caminho-da-escola-apresentacao>. Acesso em 06 de março de 2016.

FURTADO, Celso. Formação econômica do Brasil. 34 ed. São Paulo: Companhia das Letras. 2007. GIL, Antônio Carlos. Como elaborar projetos de pesquisa. 4. ed. - São Paulo : Atlas, 2002.

GREMAUD, A. P. et al. Economia Brasileira Contemporânea. 6 ed. São Paulo : Atlas, 2007. 
Id on Line Revista Multidisciplinar e de Psicologia

Id on Line Multidisciplinary and Psychology Journal

IBGE.

Área

dos

municípios

brasileiros.Disponível

em:

ftp://geoftp.ibge.gov.br/organizacao_territorial/areas_e_limites/areas_2014_xls.zip. Acesso em 29 de janeiro de 2016.

IBGE. Municípios localizados na região semiárida do Brasil. Disponível em: http://www.ibge.gov.br/home/geociencias/geografia/semiarido.shtm?c=4. Acesso em 29 de janeiro de 2016.

IBGE. MAPA DO SEMIÁRIDO BRASILEIRO - Portaria No89 do Ministério da Integração Nacional, de 16 de março de 2005 - IBGE, Malha Municipal Digital, 2005.

IBGE. Semiárido Brasileiro. Disponível em: http://www.ibge.gov.br/home/geociencias/geografia/semiarido.shtm?c=4. Acesso em 11 de fevereiro de 2016.

IBGE. Senso demográfico 2010. Disponível em: http://www.censo2010.ibge.gov.br/sinopse/index.php?dados=8> . Acesso em: 04 de março de 2016.

MINISTÉRIO DO DESENOLVIMENTO SOCIAL E COMBATE À FOME. Programas que atendem aos inscritos. Disponível em < http://mds.gov.br/assuntos/cadastro-unico/o-que-e-e-paraque-serve/programas-e-beneficios >. Acesso em 03 de março de 2016.

MINISTÉRIO DO DESENOLVIMENTO SOCIAL E COMBATE À FOME. Relatório de informações Sociais. Disponível em: < http://aplicacoes.mds.gov.br/sagi/RIv3/geral/index.php>. Acesso em 04 de março de 2016.

MINISTÉRIO DO TRABALHO E EMPREGO. Evolução do salário mínimo 1940-2016. Disponível em: http://www.mte.gov.br/images/Documentos/SalarioMinimo/EVOLEISM1940a2016.xls. Acesso em 10 de março de 2016.

PNUD. Desenvolvimento humano e IDH. Disponível em: < http://www.pnud.org.br/IDH/DH.aspx $>$. Acesso em 14 de fevereiro de 2016.

IDH.

Disponível

em

$<$

http://www.pnud.org.br/IDH/IDH.aspx?indiceAccordion=0\&li=li_IDH $>$. Acesso em 14 de fevereiro de 2016.

Ranking IDHM Unidades da Federação 1991. Disponível em: < http://www.pnud.org.br/atlas/ranking/Ranking-IDHM-UF-1991.aspx>. Acesso em: 08 de fevereiro de 2016.

Ranking IDHM Unidades da Federação 2000. Disponível em: < http://www.pnud.org.br/atlas/ranking/Ranking-IDHM-UF-2000.aspx >. Acesso em: 08 de fevereiro de 2016.

Ranking IDHM Unidades da Federação 2010. Disponível em: < http://www.pnud.org.br/atlas/ranking/Ranking-IDHM-UF-2010.aspx $>$. Acesso em: 08 de fevereiro de 2016.

Atlas do desenvolvimento Humano dos Municípios. Disponível em < http://www.pnud.org.br/IDH/Default.aspx?indiceAccordion=1\&li=li_AtlasMunicipios>. Acesso em: 29 de fevereiro de 2016. 
Id on Line Revista Multidisciplinar e de Psicologia

Id on Line Multidisciplinary and Psychology Journal

RIBEIRO, Darcy. O povo brasileiro: a formação e o sentido do Brasil. São Paulo: Companhia das letras. 2006. 13 reimp.

VERGARA, Sylvia Constant. Projetos e relatórios de pesquisas em Administração. São Paulo: Atlas. 1997.

Anexos

Anexo 1 - Ranking IDHM 1991

\begin{tabular}{|c|c|c|c|c|c|}
\hline $\begin{array}{c}\text { Ranking } \\
\text { IDHM } 1991\end{array}$ & Unidade da Federação & IDHM 1991 & $\begin{array}{l}\text { IDHM } \\
\text { Renda } \\
1991\end{array}$ & $\begin{array}{c}\text { IDHM } \\
\text { Longevidade } \\
1991\end{array}$ & $\begin{array}{l}\text { IDHM } \\
\text { Educação } \\
1991\end{array}$ \\
\hline $21^{\circ}$ & Acre & 0,402 & 0,574 & 0,645 & 0,176 \\
\hline $24^{\circ}$ & Alagoas & 0,370 & 0,527 & 0,552 & 0,174 \\
\hline $11^{\circ}$ & Amapá & 0,472 & 0,620 & 0,668 & 0,254 \\
\hline $15^{\circ}$ & Amazonas & 0,430 & 0,605 & 0,645 & 0,204 \\
\hline $22^{\circ}$ & Bahia & 0,386 & 0,543 & 0,582 & 0,182 \\
\hline $20^{\circ}$ & Ceará & 0,405 & 0,532 & 0,613 & 0,204 \\
\hline $1^{\circ}$ & Distrito Federal & 0,616 & 0,762 & 0,731 & 0,419 \\
\hline $7^{\circ}$ & Espírito Santo & 0,505 & 0,619 & 0,686 & 0,304 \\
\hline $9^{\circ}$ & Goiás & 0,487 & 0,633 & 0,668 & 0,273 \\
\hline $27^{\circ}$ & Maranhão & 0,357 & 0,478 & 0,551 & 0,173 \\
\hline $13^{\circ}$ & Mato Grosso & 0,449 & 0,627 & 0,654 & 0,221 \\
\hline $8^{\circ}$ & Mato Grosso do Sul & 0,488 & 0,641 & 0,699 & 0,259 \\
\hline $10^{\circ}$ & Minas Gerais & 0,478 & 0,618 & 0,689 & 0,257 \\
\hline $17^{\circ}$ & Pará & 0,413 & 0,567 & 0,640 & 0,194 \\
\hline $23^{\circ}$ & Paraíba & 0,382 & 0,515 & 0,565 & 0,191 \\
\hline $6^{\circ}$ & Paraná & 0,507 & 0,644 & 0,679 & 0,298 \\
\hline $14^{\circ}$ & Pernambuco & 0,440 & 0,569 & 0,617 & 0,242 \\
\hline $26^{\circ}$ & Piauí & 0,362 & 0,488 & 0,595 & 0,164 \\
\hline $3^{\circ}$ & Rio de Janeiro & 0,573 & 0,696 & 0,690 & 0,392 \\
\hline $16^{\circ}$ & Rio Grande do Norte & 0,428 & 0,547 & 0,591 & 0,242 \\
\hline $5^{\circ}$ & Rio Grande do Sul & 0,542 & 0,667 & 0,729 & 0,328 \\
\hline $19^{\circ}$ & Rondônia & 0,407 & 0,585 & 0,635 & 0,181 \\
\hline $12^{\circ}$ & Roraima & 0,459 & 0,643 & 0,628 & 0,240 \\
\hline $4^{\circ}$ & Santa Catarina & 0,543 & 0,648 & 0,753 & 0,329 \\
\hline $2^{\circ}$ & São Paulo & 0,578 & 0,729 & 0,730 & 0,363 \\
\hline $18^{\circ}$ & Sergipe & 0,408 & 0,552 & 0,581 & 0,211 \\
\hline $25^{\circ}$ & Tocantins & 0,369 & 0,549 & 0,589 & 0,155 \\
\hline
\end{tabular}

Fonte: Altas do Desenvolvimento Humano no Brasil (2013). 
Id on Line Revista Multidisciplinar e de Psicologia

Id on Line Multidisciplinary and Psychology Journal

Anexo 2 - Ranking IDHM 2010

\begin{tabular}{|c|c|c|c|c|c|}
\hline $\begin{array}{l}\text { Ranking } \\
\text { IDHM } 2010\end{array}$ & Unidade da Federação & $\begin{array}{c}\text { Ranking } \\
\text { IDHM } \\
2010\end{array}$ & $\begin{array}{l}\text { IDHM } \\
\text { Renda } \\
2010\end{array}$ & $\begin{array}{c}\text { IDHM } \\
\text { Longevidade } \\
2010\end{array}$ & $\begin{array}{l}\text { IDHM } \\
\text { Educação } \\
2010\end{array}$ \\
\hline $21^{\circ}$ & Acre & 0,663 & 0,671 & 0,777 & 0,559 \\
\hline $27^{\circ}$ & Alagoas & 0,631 & 0,641 & 0,755 & 0,520 \\
\hline $12^{\circ}$ & Amapá & 0,708 & 0,694 & 0,813 & 0,629 \\
\hline $18^{\circ}$ & Amazonas & 0,674 & 0,677 & 0,805 & 0,561 \\
\hline $22^{\circ}$ & Bahia & 0,660 & 0,663 & 0,783 & 0,555 \\
\hline $17^{\circ}$ & Ceará & 0,682 & 0,651 & 0,793 & 0,615 \\
\hline $1^{\circ}$ & Distrito Federal & 0,824 & 0,863 & 0,873 & 0,742 \\
\hline $7^{\circ}$ & Espírito Santo & 0,740 & 0,743 & 0,835 & 0,653 \\
\hline $8^{\circ}$ & Goiás & 0,735 & 0,742 & 0,827 & 0,646 \\
\hline $26^{\circ}$ & Maranhão & 0,639 & 0,612 & 0,757 & 0,562 \\
\hline $11^{\circ}$ & Mato Grosso & 0,725 & 0,732 & 0,821 & 0,635 \\
\hline $10^{\circ}$ & Mato Grosso do Sul & 0,729 & 0,740 & 0,833 & 0,629 \\
\hline $9^{\circ}$ & Minas Gerais & 0,731 & 0,730 & 0,838 & 0,638 \\
\hline $24^{\circ}$ & Pará & 0,646 & 0,646 & 0,789 & 0,528 \\
\hline $23^{\circ}$ & Paraíba & 0,658 & 0,656 & 0,783 & 0,555 \\
\hline $5^{\circ}$ & Paraná & 0,749 & 0,757 & 0,830 & 0,668 \\
\hline $19^{\circ}$ & Pernambuco & 0,673 & 0,673 & 0,789 & 0,574 \\
\hline $24^{\circ}$ & Piauí & 0,646 & 0,635 & 0,777 & 0,547 \\
\hline $4^{\circ}$ & Rio de Janeiro & 0,761 & 0,782 & 0,835 & 0,675 \\
\hline $16^{\circ}$ & Rio Grande do Norte & 0,684 & 0,678 & 0,792 & 0,597 \\
\hline $6^{\circ}$ & Rio Grande do Sul & 0,746 & 0,769 & 0,840 & 0,642 \\
\hline $15^{\circ}$ & Rondônia & 0,690 & 0,712 & 0,800 & 0,577 \\
\hline $13^{\circ}$ & Roraima & 0,707 & 0,695 & 0,809 & 0,628 \\
\hline $3^{\circ}$ & Santa Catarina & 0,774 & 0,773 & 0,860 & 0,697 \\
\hline $2^{\circ}$ & São Paulo & 0,783 & 0,789 & 0,845 & 0,719 \\
\hline $20^{\circ}$ & Sergipe & 0,665 & 0,672 & 0,781 & 0,560 \\
\hline $14^{\circ}$ & Tocantins & 0,699 & 0,690 & 0,793 & 0,624 \\
\hline
\end{tabular}

Fonte: Altas do Desenvolvimento Humano no Brasil (2013).

Anexo 3 - Variação Percentualdos Índices Entre 1991 E 2010

\begin{tabular}{|c|c|c|c|c|}
\hline Unidade da Federação & Var. IDHM & $\begin{array}{l}\text { Var. IDHM } \\
\text { Renda }\end{array}$ & $\begin{array}{l}\text { Var. IDHM } \\
\text { Longevidade }\end{array}$ & $\begin{array}{l}\text { Var. IDHM } \\
\text { Educação }\end{array}$ \\
\hline Acre & $64,93 \%$ & $16,90 \%$ & $20,47 \%$ & $217,61 \%$ \\
\hline Alagoas & $70,54 \%$ & $21,63 \%$ & $36,78 \%$ & $198,85 \%$ \\
\hline Amapá & $50,00 \%$ & $11,94 \%$ & $21,71 \%$ & $147,64 \%$ \\
\hline Amazonas & $56,74 \%$ & $11,90 \%$ & $24,81 \%$ & $175,00 \%$ \\
\hline Bahia & $70,98 \%$ & $22,10 \%$ & $34,54 \%$ & $204,95 \%$ \\
\hline Ceará & $68,40 \%$ & $22,37 \%$ & $29,36 \%$ & $201,47 \%$ \\
\hline Distrito Federal & $33,77 \%$ & $13,25 \%$ & $19,43 \%$ & $77,09 \%$ \\
\hline
\end{tabular}


Id on Line Revista Multidisciplinar e de Psicologia

Id on Line Multidisciplinary and Psychology Journal

\begin{tabular}{|l|r|r|r|r|} 
Espírito Santo & $46,53 \%$ & $20,03 \%$ & $21,72 \%$ & $114,80 \%$ \\
\hline Goiás & $50,92 \%$ & $17,22 \%$ & $23,80 \%$ & $136,63 \%$ \\
\hline Maranhão & $78,99 \%$ & $28,03 \%$ & $37,39 \%$ & $224,86 \%$ \\
\hline Mato Grosso & $61,47 \%$ & $16,75 \%$ & $25,54 \%$ & $187,33 \%$ \\
\hline Mato Grosso do Sul & $49,39 \%$ & $15,44 \%$ & $19,17 \%$ & $142,86 \%$ \\
\hline Minas Gerais & $52,93 \%$ & $18,12 \%$ & $21,63 \%$ & $148,25 \%$ \\
\hline Pará & $56,42 \%$ & $13,93 \%$ & $23,28 \%$ & $172,16 \%$ \\
\hline Paraíba & $72,25 \%$ & $27,38 \%$ & $38,58 \%$ & $190,58 \%$ \\
\hline Paraná & $47,73 \%$ & $17,55 \%$ & $22,24 \%$ & $124,16 \%$ \\
\hline Pernambuco & $52,95 \%$ & $18,28 \%$ & $27,88 \%$ & $137,19 \%$ \\
\hline Piauí & $78,45 \%$ & $30,12 \%$ & $30,59 \%$ & $233,54 \%$ \\
\hline Rio de Janeiro & $32,81 \%$ & $12,36 \%$ & $21,01 \%$ & $72,19 \%$ \\
\hline Rio Grande do Norte & $59,81 \%$ & $23,95 \%$ & $34,01 \%$ & $146,69 \%$ \\
\hline Rio Grande do Sul & $37,64 \%$ & $15,29 \%$ & $15,23 \%$ & $95,73 \%$ \\
\hline Rondônia & $69,53 \%$ & $21,71 \%$ & $25,98 \%$ & $218,78 \%$ \\
\hline Roraima & $54,03 \%$ & $8,09 \%$ & $28,82 \%$ & $161,67 \%$ \\
\hline Santa Catarina & $42,54 \%$ & $19,29 \%$ & $14,21 \%$ & $111,85 \%$ \\
\hline São Paulo & $35,47 \%$ & $8,23 \%$ & $15,75 \%$ & $98,07 \%$ \\
\hline Sergipe & $62,99 \%$ & $21,74 \%$ & $34,42 \%$ & $165,40 \%$ \\
\hline Tocantins & $89,43 \%$ & $25,68 \%$ & $34,63 \%$ & $302,58 \%$ \\
\hline Fonte: Altas & 42,0 & & \\
\hline
\end{tabular}

Fonte: Altas do Desenvolvimento Humano no Brasil (2013).

\section{Como citar este artigo (Formato ABNT):}

CUNHA, U.A.N.; FERREIRA, L.C. IDHM dos Estados da Região Nordeste do Brasil: Histórico e Análise entre 1991 e 2010. Id on Line Revista Multidisciplinar e de Psicologia, Julho de 2016, vol.,10 n.30, Supl 1. p. 168181. ISSN 1981-1179.

Recebido: $14 / 04 / 2016$

Aceito: 20/04/2016 